\title{
Cases of Road Traffic Accident in Nigeria: A Time Series Approach
}

\author{
Ridwan A. Sanusi $i^{*}$ \\ F.B. Adebola² \\ N.A. Adegoke 1,2 \\ ${ }^{1}$ Department of Mathematics and Statistics, King Fahd University of Petroleum and Minerals, Saudi Arabia \\ ${ }^{2}$ Department of Statistics, Federal University of Technology Akure Nigeria \\ "Email of the corresponding author: amhigher2010@yahoo.com
}

Doi:10.5901/mjss.2016.v7n2s1p542

\section{Abstract}

Road traffic accident in Nigeria is increasing at a disturbing rate and has raised one of the country major concerns. We provide appropriate and suitable time series model for the cases of road accident; the minor cases, the serious cases, the fatal cases and the total cases of road accident in Nigeria. The most widely used conventional method of time series known as Autoregressive Integrated Moving Average (ARIMA) model (also known as Box-Jenkins method) is applied to the annual cases of road accident data in Nigeria from 1960-2013, to determine patterns of road traffic accident cases along the Nigeria motorway. Appropriate models are developed for the minor cases, the serious cases, the fatal cases and the total cases. ARIMA $(1,1,1)$ model is obtained for the minor and total cases, ARIMA $(1,1,0)$ model is obtained for the serious cases, while ARIMA $(0,1,1)$ model is obtained for the fatal cases using data from 1960-2011. Data from 2012 to 2013 is used to test the adequacy and performance of the models. The models are then used to forecast the different cases from 2014 till 2020, and the forecast show an average increase in the data for the cases considered.

Keywords: ARIMA, Forecast, Minor, Fatal, Serious, Total.

\section{Introduction}

Road traffic accident is an issue of concern in Nigeria, and the world at large, which accounts for over one million death in the world yearly. The World Health Organization (WHO) classified road traffic accident as one of the top ten causes of death in the world, using International Statistical Classification of Diseases and Related Health Problems (ICD) (Organization, 2013). The Global status report on road safety 2013 presents information on road safety from 182 countries, accounting for almost $99 \%$ of the world's population (Organization, 2013). The report indicates that worldwide, the total number of death due to road traffic remains unacceptably high at 1.24 million per year. Only 28 countries, covering $7 \%$ of the world's population, have comprehensive road safety laws on five key risk factors: drinking and driving, speeding, failing to use motorcycle helmets, failing to use seat-belts, and child restraints (Organization, 2013). Cases of road traffic accident is increasing in recent years in Nigeria, due to nonchalant attitude of the government to road construction, and violation of traffic rules by motor users in the country. This shows that the causes of road traffic accident are multi-factorial, ranging from government factor (inability to construct motorable roads), drivers' factor (violating traffic rules; exceeding speed limit, using out-modeled cars, drinking or making mobile call while driving, etc). Use of Motorbikes had inflated the number of road traffic accident cases until recently when some state government banned their usage on major roads in Nigeria. These cases will increase to an alarming rate if government do not pay attention to construction of roads and providing strong penalties against road traffic violators.

WHO forecasted that about 21548 and 20404 deaths will occur due to road traffic accident in 2011 and 2013 respectively (Promotion \& Prevention, 2013). Boakye Agyemang (Agyemang, Abledu, \& Semevoh, 2013) worked on the statistical analysis of the systematic yearly increase in the number of accidents. He used data on yearly road traffic accidents and population values of Ghana for the period 1990 to 2012, and found out the following; a systematic obvious pattern of growth in both road traffic accidents and population for the year 1990 to 2012; a strong positive correlation between road traffic accidents and population for the year 1990 to 2012; and a regression model for estimating and forecasting the data.

David Krivec et al in a conference in Republic of Slovenia for Road Safety in 2005, used ARIMA $(1,0,0)(0,1,1)_{12}$ 
with constant and regressor for a short-term forecast of fatalities and severely injured persons involved in road traffic accidents in Slovenia (Series et al., 2006). Box-Jenkins approach was used to analyze annual road accident data between 1980 and 2010 to determine the patterns of road traffic accident cases, injuries and deaths along the AccraTema motorway (Okutu, 2011). They used ARIMA $(1,1,1)$ to fit injury and death data while accident cases data ware modelled with ARIMA $(0,1,2)$. The forecast of their models showed that the cases will continue to increase.

Frequency of traffic related mortalities is increasing worldwide. It was estimated that by continuing the current trends for road traffic accidents to 2020 , proportion of deaths will increase up to $83 \%$ in middle and low income countries and up to $27 \%$ in high-income communities (Peden, 2004), (Mohan, Padmanabhan, \& Ramjee, 2008). In the middle and low income countries, there will be about $83 \%$ increase in the proportion of death, and about $27 \%$ increase in the proportion of death in the high-income communities by 2020 if the current trend of road accidents continues.

Short-term traffic volume forecast can be carried out using one of the newly opined time series methods. Nihan \& Holmesland, 1980 fits model on monthly volume on a freeway segment from year 1968 to year 1976, and used the model to forecast for year 1977. They compared the result with the actual volume of 1977 , and concluded that time series technique can be used to accurately and inexpensively forecast data for short time.

Time series analysis is a method of describing the inherent nature of data over time, and using it to predict the future (Hosseini, Yavarifar, \& Yavarifar, 2014). The basic approaches to forecasting time series data are the selfprojecting time series approach and the cause-and-effect time series approach. The former uses only the time series data for forecasting while the latter relies on the inherent series assumed to cause the pattern of the original series. Moreover, the self-projecting time series approach is not expensive to apply, it requires less data and it performs better for short and long-term forecast. The univariate version of Box-Jenkins method is a self-projecting time series forecasting method, hence, we adopt the Box-Jenkins method to explain and model our data. This requires the data to be stationary, and differencing will be used to make the data stationary if it is not stationary.

This study provides appropriate and suitable time series model for the cases of road accident; the minor cases, the serious cases, the fatal cases and the total cases of road accident in Nigeria. The most widely used conventional method of time series known as Box-Jenkins method is applied to the annual cases of road accident data in Nigeria from 19602013, to determine patterns of road traffic accident cases along the Nigeria's motorway.

\section{Materials and Method}

Data used for the analyses was collected from Federal Road Safety Corps (FRSC), Nigeria. FRSC is the body in charge of road safety administration such as ensuring safety of motorists on roads, teaching the general public on the etiquettes of highway, recommending devices meant for reducing accidents on the highways, among others. Accidents caused by road traffic are in different cases, ranging from the minor cases, the serious cases to the fatal cases. In this paper, we collected data from 1960 to 2013 and data from 1960 to 2011 will be used to model the cases of road accident; the minor cases, the serious cases and the fatal cases, and data from 2012 to 2013 will be used for model validation, while the models are used to forecast the future cases of road accidents from 2014 to 2020. Box-Jenkins method will be used to derive models for forecasting these data. This method is preferred because of its high accuracy in forecasting data, especially within a short to medium term period. Its model simplicity gives it an advantage of cost and response time, because high cost is required to run and set up complex models (Nihan \& Holmesland, 1980).

\section{Model Building}

In theory, Auto-regressive Integrated Moving Averages ARIMA Models (Box Jenkins) are the most universal class of models for forecasting a time series data. As proposed by Box and Jenkins, that in general, forecasting based on ARIMA models comprises of three different steps:

Model Identification, Parameter estimation and Diagnostic checking. Until a desirable model for the data is identified, the three steps will be repeated (Box, Jenkins, \& MacGregor, 1974). The method of Box and Jenkins dictates an iterative process requiring a sound understanding of time series analysis technique, some degree of judgement and many rounds of trials $(\mathrm{Wu}, 2013)$. Meanwhile, It is worth mentioning here that because of the volume of the work, the best models out of several competing models that explain the variables under study are included in the work. 

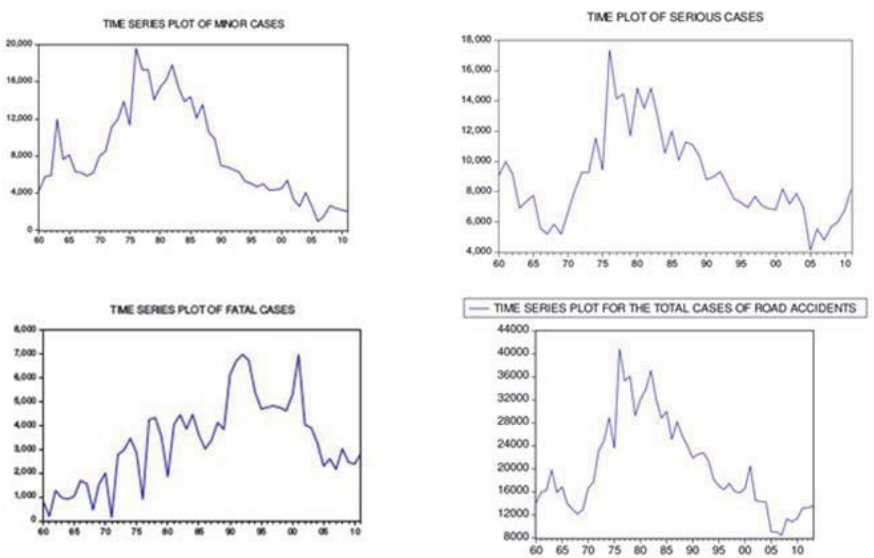

Figure 1: Time Series Plots of Minor, Serious, fatal and Total Cases of Road Accidents

Figure (1) shows the time plots of the minor cases, the serious cases, the fatal cases and the total cases of road traffic accident in Nigeria from year 1960 to 2013. The series exhibit non-stationary behaviour.

\subsection{Unit root test}

Also, the series were tested for stationarity by using the unit root test. Figure (2) and Figure (3) show that the series are insignificant with $p$-values greater than $5 \%$. Hence, there is need to difference the data so as to make it stationary. The time series plot of the first difference series are shown in Figure (4).
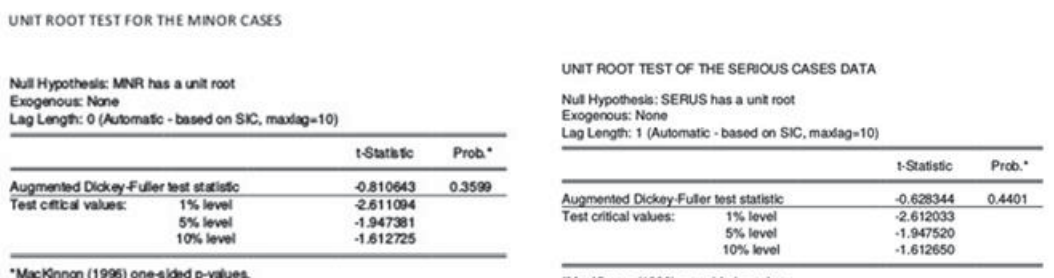

"Mackennon (1996) onesided p-values.

Mackinnon (1996) one-sided praives.

Figure 2: Unit Root Tests of Minor and Serious Cases of Road Accidents

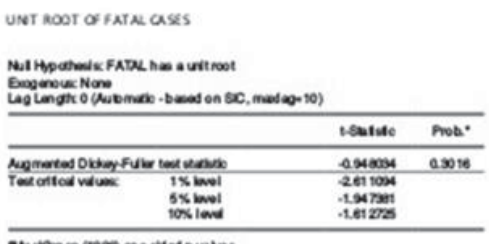

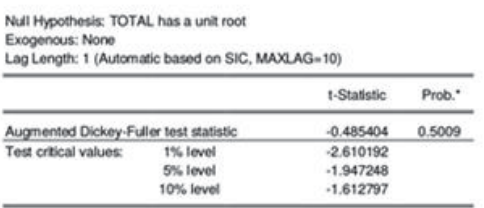

"Mackinnon (1996) one-sided pvalues.

Figure 3: Unit Root Tests of fatal and Total Cases of Road Accidents

The correlogram plots of the first difference, in Figure (5) appear to be stationary with significant spikes within the first two lags. These are buttressed by the unit root tests of the series in Figure (6). The probability values of the unit root tests are all below 5\%, indicating that the data are now stationary. The order of the ARIMA models would be guessed from the correlogram plots to determine the best models to model the series. 

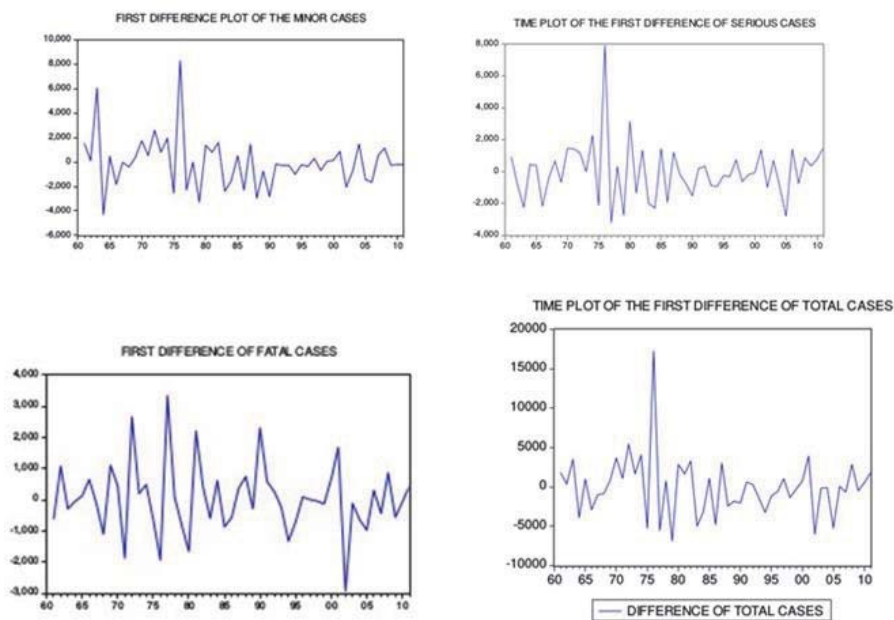

Figure 4: Time Series Plot of the First Difference for The Minor, Serious, fatal and Total Cases of Road Accidents

\subsection{Model Outputs}

From the correlogram plots in Figure (5), many competing models were guessed. Out of all the competing models, the best models for minor, serious, fatal and total cases of road accident are ARIMA $(1,1,1), \operatorname{ARIMA}(1,1,0), \operatorname{ARIMA}(0,1,1)$ and ARIMA $(1,1,1)$ respectively.

The outputs are displayed in Figure (7). All the variables are significants and their respective Durbin-Watson statistics values are close to 2 , suggesting that some of the serial correlation were eliminated in the error terms. The error terms are not serially correlated (because the error terms of a good model must not be serially correlated). Moreover, the R-squared value, which tells us the percentage of the dependent variable that is explained by the independent(s) variable(s), is low. This indicates that a differenced data is harder to fit than a level data.

\section{Residual Diagnostic}

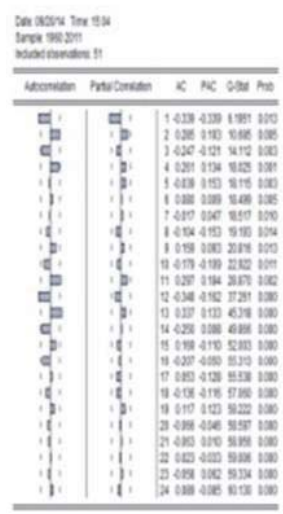

\begin{tabular}{|c|c|c|c|c|c|c|}
\hline Autocorrilation & Panal Contianon & & $A C$ & PAC & - $-50 t$ & Prob \\
\hline 땀, & $\Leftrightarrow$, & 1 & .0 .493 & .0 .493 & 10.122 & 0.001 \\
\hline . & ip. & 2 & 0.297 & 0.05 & 14974 & 0.001 \\
\hline E. & 1. & 3 & $\$ 221$. & -0005 & 17736 & 0.000 \\
\hline B & , b, & & 0218 & 0000 & 20.473 & 0000 \\
\hline if: & ; i & & -0.001 & 0.000 & 20059 & 0.001 \\
\hline ib: & , i & s & 0.140 & 0.107 & 22005 & 0001 \\
\hline id, & $1 \%$ & & 0.110 & .021 & 22971 & 0.002 \\
\hline , व 1 & 뭉 & $:$ & 0.152 & -0.321 & 24.624 & 0002 \\
\hline , ]. & 7. & 9 & 0.113. & 0021 & 25262 & 0003 \\
\hline 모', & id, & 10 & 0.197. & -150 & 27000 & 0.002 \\
\hline , p. & 17 & 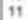 & 0125 & -0.051 & 20650 & 0.002 \\
\hline 15. & 卢 & 12 & 0.019 & 0.285 & 28 ans & 0004 \\
\hline id i & is: & $n$ & 0.137 & 0 tos & 30220 & 0.004 \\
\hline , दै, & a: & 14 & 0114. & -0231 & 31.182 & 0005 \\
\hline , b. & & 15 & o111 & 0021 & 32111 & 0.006 \\
\hline ; $;$ & i, & 16 & 0000 & 0007 & 32116 & 0.010 \\
\hline 11. & id. & 17 & $-0,030$. & -0.075 & 32205 & 0.014 \\
\hline id? & a. & ie & 0.007. & -02200 & 22020 & 0010 \\
\hline & $1 \mathrm{p}$ & 19 & 0016 & 0,100 & 32202 & 0025 \\
\hline i. ब, & .1. & 20 & 0004. & .0000 & 33.453 & 0.030 \\
\hline bi & i, & 21 & 0.194. & -0032 & 36459 & 0.019 \\
\hline , क्ष' & 1,1 & 22 & 0.140 & 0.089 & 30.312 & 0.017 \\
\hline & id, & 20 & 0.030. & -2130 & 30410 & 0.020 \\
\hline 1.1. & .7. & 24 & 0020 & .0030 & 32.450 & 0.031 \\
\hline
\end{tabular}



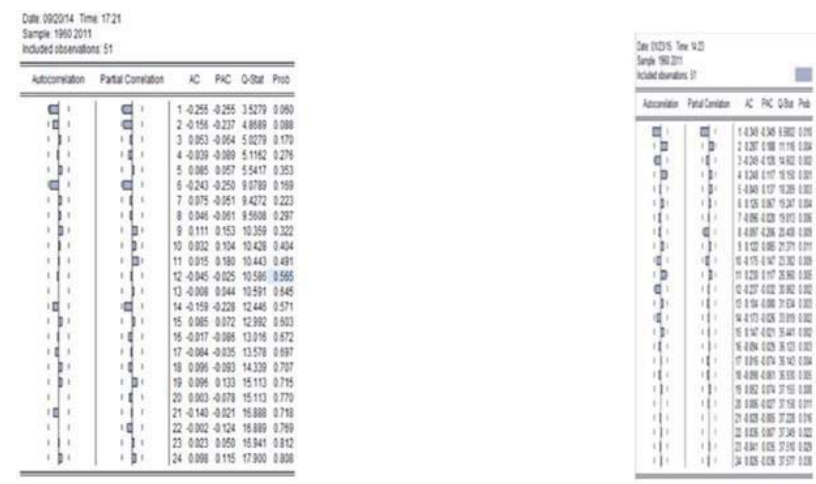

Figure 5: Correlogram Plot for the first difference of the Minor, Serious, fatal and Total Cases of Road Accidents

Figure (8) and Figure (9) show the correlogram plots of residuals for the best models of the series. The probability values of the Q-statistics are all greater than $5 \%$, indicating that the residuals are all White Noise, that is, they are not forecastable. Model with a non-forecastable residuals will yield a good out-sample forecast with minimum error. The residual plots are shown in Figure (10), the random effect of the residuals are evident in the plots.
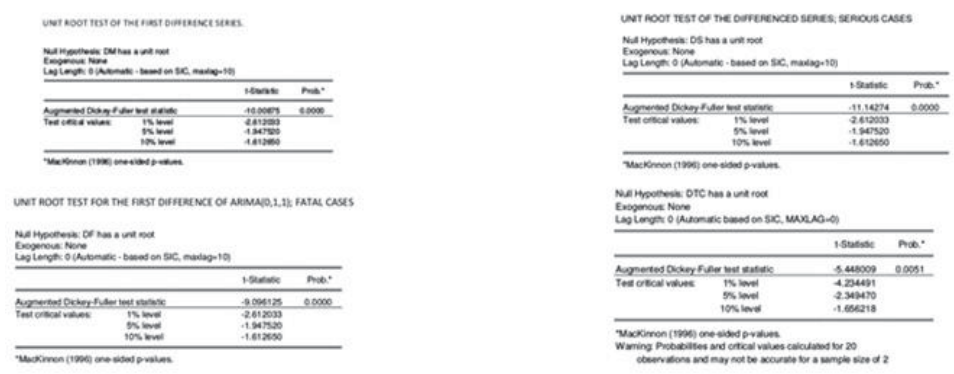

Figure 6: Unit Root Tests of the First Difference of Minor, Serious, fatal and Total Cases of Road Accidents
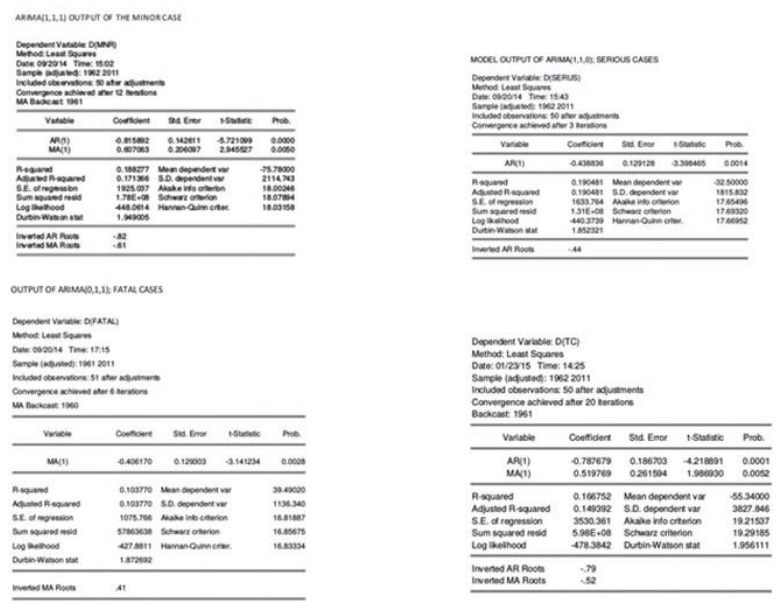

Figure 7: Time Series Models for Minor, Serious, fatal and Total Cases of Road Accidents 


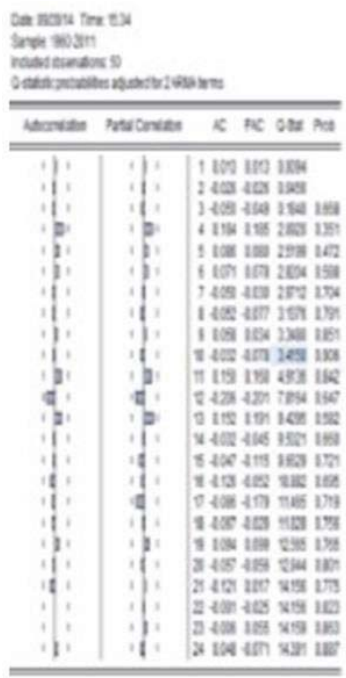

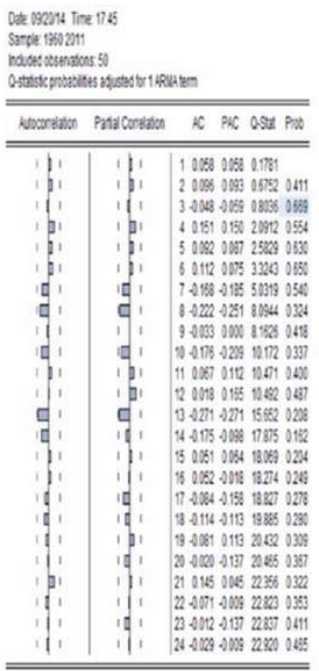

Figure 8: Correlogram Plot of the Residuals for Minor and Serious cases of Road Accidents

The plots of the unit root tests in Figure (11) show that the inverted roots of the selected models are all within a unit circle. For an ARIMA model to be stationary and invertible, the inverted roots of the AR and MA respectively, must be less than one. Hence, we can say our models are stationary and invertible (as the case may be).

The in-sample forecast evaluation of the models, Figure (13) shows that the Bias proportions, which measure the level of systematic error, are close to zero. The variance proportions are also close to zero (a high value will imply that the variance of the original series is greater than that of the forecast series), and the covariance proportions, which measure the degree of forecast error that can be credited to the random nature of the forecast series are very close to one in all cases. The sum total of the bias, variance and covariance proportion must be one.

As a result of this, we have a good In-sample forecast plot in Figure (12).

\begin{tabular}{|c|c|c|}
\hline & & 1 0156 USB 1286 \\
\hline 101 & 101 & $2413+1301807$ 0281 \\
\hline 111 & 171 & 32011 COS 1085 O58 \\
\hline 111 & if & 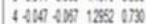 \\
\hline 111 & $1] 1$ & 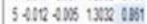 \\
\hline di & di & 54244264316 U5\% \\
\hline 111 & 1) & 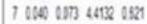 \\
\hline 161 & if & 8018 UNe 56159 o6. \\
\hline 10 & 10 & $9019102477841 \mathrm{cos}$ \\
\hline 151 & 11 & 1) 011 coa 8594 cos \\
\hline 11 & 11 & 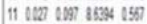 \\
\hline 111 & 101 & 24664986360 \\
\hline if & 111 & 13 ALS ABS 9506 6551 \\
\hline 101 & at 1 & 14.1342001200052 \\
\hline 171 & 121 & 15 000 6115 22074 $05 x$ \\
\hline 111 & 101 & 15 -10x 2118 12:41 050 \\
\hline 111 & 171 & 17 SLE \&1B 1230 OTL \\
\hline $1 \mathrm{gi}$ & 111 & 13018 20131 3360 $15 \%$ \\
\hline 10 & 111 & 190180115515065 \\
\hline $1[1$ & 101 & 2) 1006213515120124 \\
\hline 1] 1 & 111 & 21 4158 4019 1736053 \\
\hline 111 & if 1 & 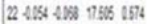 \\
\hline 11. & 101 & 23018 18 \\
\hline 111 & 111 & 24 0LE UNB 7762 CY \\
\hline
\end{tabular}

\begin{tabular}{|c|c|c|}
\hline & & 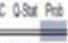 \\
\hline 17 & 111 & 1104104015 \\
\hline 111 & 11 & $24 w 120010$ \\
\hline 11 & 111 & J ABAB IVE OF \\
\hline iti & $1 \mathrm{a}$, & 4130100102 \\
\hline 151 & 151 & $51 \% 1 \% 165$ ose \\
\hline 151 & 15 & 6 \\
\hline ifi & ifi & 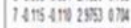 \\
\hline if 1 & it) & $16 \% 40130 \%$ an \\
\hline 111 & 111 & 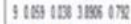 \\
\hline if & id 1 & 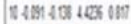 \\
\hline 101 & 13 & i1 6 (1) is $5 \mathrm{ma}$ on \\
\hline idi & if 1 & 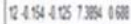 \\
\hline 111 & 111 & 1020126 162 or \\
\hline ifi & 111 & 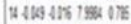 \\
\hline 111 & 111 & 8106450 IIS UR \\
\hline 111 & 111 & S4R: IN IVE ด \\
\hline if 1 & if & 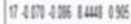 \\
\hline 11 & 111 & 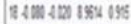 \\
\hline 111 & 11 & 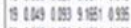 \\
\hline 11 & 11 & 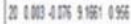 \\
\hline 111 & 111 & 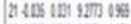 \\
\hline 111 & 111 & 2 เ \\
\hline 11 & 111 & 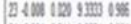 \\
\hline 111 & 111 & 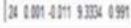 \\
\hline
\end{tabular}

Figure 9: Correlogram Plot of the Residuals Fatal and Total Cases of Road Accidents 

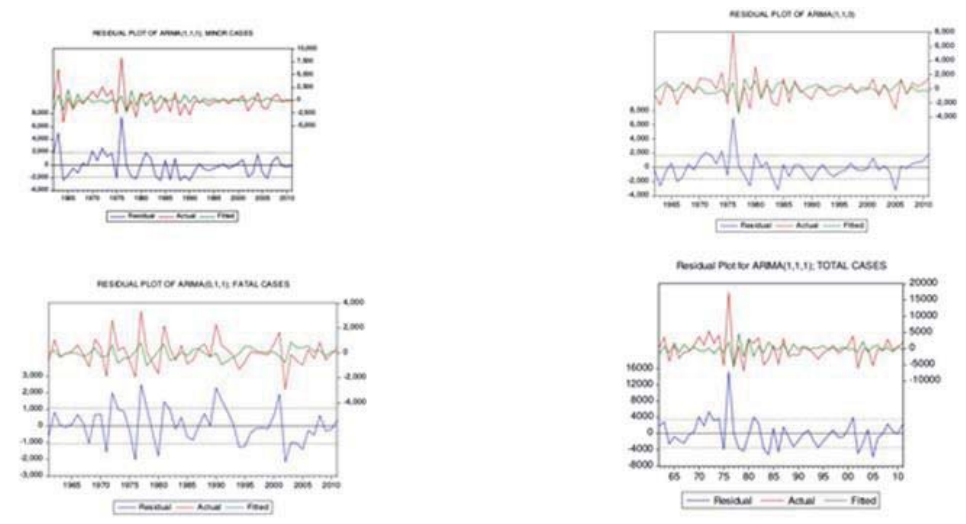

Figure 10: Residual Plots of Minor, Serious, fatal and Total Cases of Road Accidents
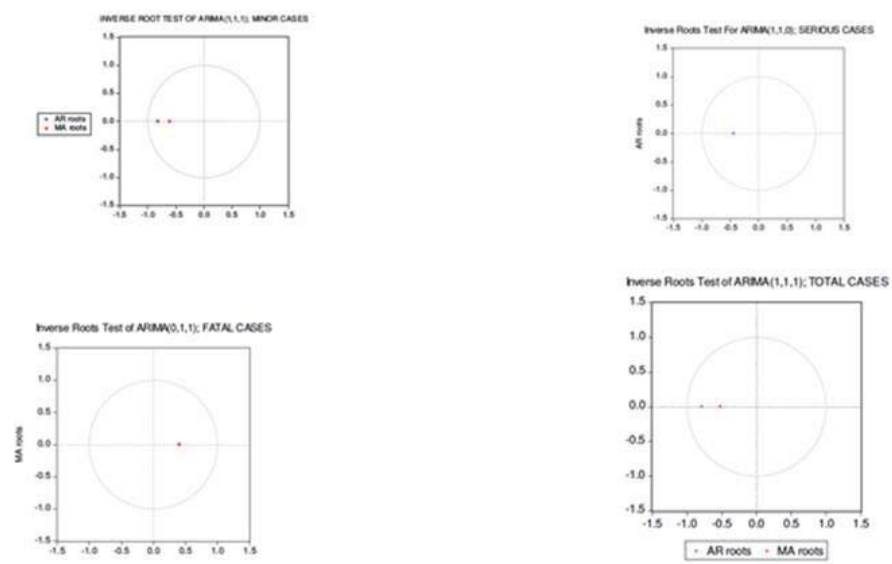

Figure 11: Unit Root Tests of Minor, Serious, fatal and Total Cases of Road Accidents
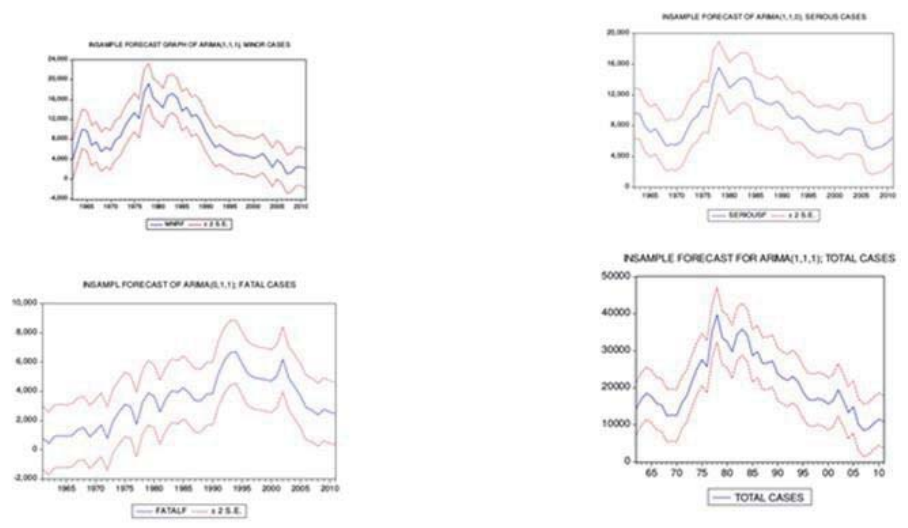

Figure 12: In-sample Forecast Plot of Minor, Serious, fatal and Total Cases of Road Accidents 
Table 1: Validation Table for ARIMA(1,1,1) Model of Minor Cases.

\begin{tabular}{|c|c|c|c|}
\hline Year & Minor Cases & Forecast & \% Variation \\
\hline 2012 & 2050 & 2065.14 & $0.74 \%$ \\
\hline 2013 & 1700 & 1711.18 & $0.66 \%$ \\
\hline
\end{tabular}
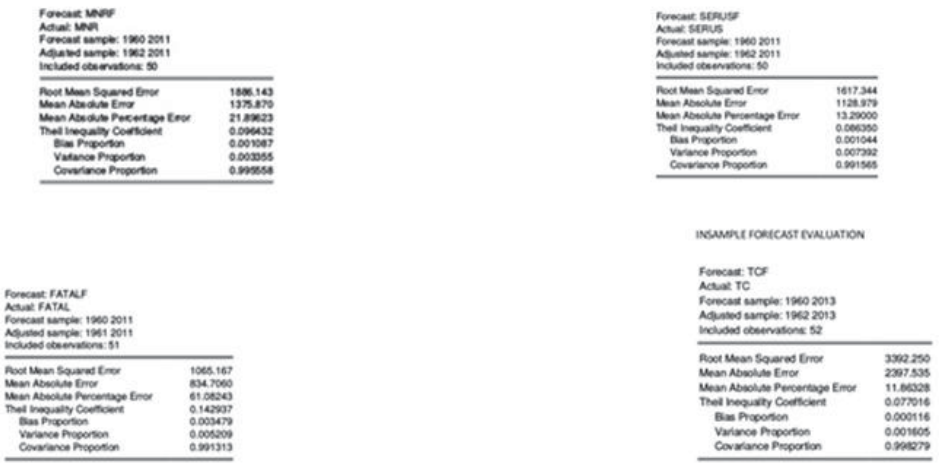

Figure 13: In-sample Forecast Evaluation of Minor, Serious, fatal and Total Cases of Road Accidents

\section{Model Forecast}

After determining the best-fit model for the series and estimating related parameters, the third phase of Box-Jenkins fitting model was evaluated for series prediction.

Using the ARIMA (1,1,1) model, the model predicted that in 2012 an approximately 2066 minor cases, this gives $0.74 \%$ percentage increase when compared with the real value of 2050 minor cases. Also, the model predicted that in 2013 an approximately 1712 minor cases, this gives $0.66 \%$ percentage increament when compared with the real value of 1700 Minor cases as given in Table (1).

Table 2: Validation Table for ARIMA(1,1,0) Model of Serious Cases.

\begin{tabular}{|c|c|c|c|}
\hline Year & Serious Cases & Forecast & \% Variation \\
\hline 2012 & 8277 & 7680.32 & $-7.21 \%$ \\
\hline 2013 & 8589 & 7977.27 & $-7.12 \%$ \\
\hline
\end{tabular}

Using the ARIMA $(1,1,0)$ model, the model predicted that in 2012 an approximately 7681 serious cases, this gives $7.21 \%$ percentage decrease when compared with the real value of 8277 serious cases. Also, the model predicted that in 2013 an approximately 7978 Serious cases, this gives $7.12 \%$ percentage decrease when compared with the real value of 8589 serious cases as given in Table (2).

Table 3: Validation Table for ARIMA $(0,1,1)$ Model of Fatal Cases.

\begin{tabular}{|c|c|c|c|}
\hline Year & Fatal Cases & Forecast & \% Variation \\
\hline 2012 & 2935 & 2688.66 & $-8.391 \%$ \\
\hline 2013 & 3294 & 2688.66 & $-18.38 \%$ \\
\hline
\end{tabular}

The ARIMA $(0,1,1)$ model predicted the same value of fatal cases of road accident, in 2012 and 2013, approximately 2689 fatal cases were predicted as shown in Table (3). These led to $8.39 \%$ and $18.38 \%$ percentage decrease in fatal cases of road accident. The constant predicted values are due to the nature of the forecasting model for the cases, since moving average model is not forecastable for the first difference. 
Table 4: Validation Table for ARIMA $(1,1,1)$ Model of Total Cases.

\begin{tabular}{|c|c|c|c|}
\hline Year & Total Cases & Forecast & \% Variation \\
\hline 2012 & 13262 & 12962.39 & $-2.26 \%$ \\
\hline 2013 & 13583 & 13146.40 & $-3.21 \%$ \\
\hline
\end{tabular}

Conclusively, using the ARIMA $(1,1,1)$ model, the model predicted that in 2012 an approximately 12963 total cases, this gives $2.26 \%$ percentage decrease when compared with the real value of 13262 . Also, the model predicted an approximately 13147 of Total cases in 2013, this gives 3.21\% percentage decrease when compared with the real value of 13583 total cases as given in Table (4).

Table 5: Forecast Table for The Cases Considered.

\begin{tabular}{|c|c|c|c|c|}
\hline Year & Minor Cases & Serious Cases & Fatal Cases & Total Cases \\
\hline 2014 & 1803.93 & 7846.95 & 2688.66 & 13001.46 \\
\hline 2015 & 1719.13 & 7904.14 & 2688.66 & 13115.62 \\
\hline 2016 & 1788.32 & 7879.05 & 2688.66 & 13025.70 \\
\hline 2017 & 1731.87 & 7890.06 & 2688.66 & 13096.53 \\
\hline 2018 & 1777.93 & 7885.23 & 2688.66 & 13040.74 \\
\hline 2019 & 1740.35 & 7887.35 & 2688.66 & 13084.68 \\
\hline 2020 & 1771.01 & 7886.41 & 2688.66 & 13050.07 \\
\hline
\end{tabular}
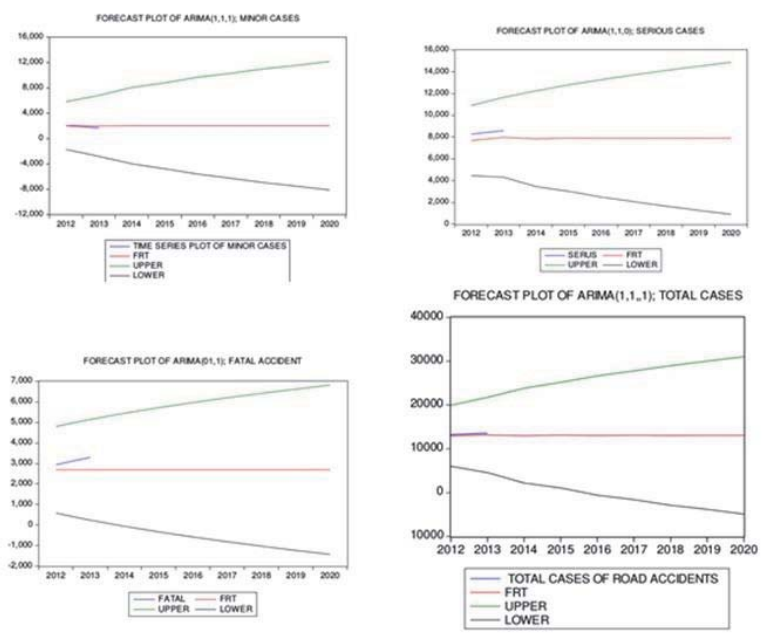

Figure 14: Forecast plots of Minor, Serious, fatal and Total Cases of Road Accidents

\section{Model Representation}

The general difference of ARIMA (1,1,1); minor cases, is given as,

$Y_{t}-Y_{t-1}=\psi\left(Y_{t-1}-Y_{t-2}\right)+e_{t}-\theta e_{t-1}$

$Y_{t}=(1+\psi) Y_{t-1}-\psi Y_{t-2}+e_{t}-\theta e_{t-1}$

Substituting the values of $\psi$ and $\theta$ as given in Figure (7), the model for the minor cases becomes,

$Y_{t}=1.815892 Y_{t-1}-0.815892 Y_{t-2}+e_{t}-0.607063 e_{t-1}$

Furthermore, the general difference of ARIMA $(1,1,0)$; serious cases, is given as,

$Y_{t}-Y_{t-1}=\psi\left(Y_{t-1}-Y_{t-2}\right)+e_{t}$

$Y_{t}=(1+\psi) Y_{t-1}-\psi Y_{t-2}+e_{t}$

Substituting the value of $\psi$ as given in Figure (7), the model for the serious cases becomes,

$Y_{t}=0.561164 Y_{t-1}+0.438836 Y_{t-2}+e_{t}$

(4) 
Also, the general difference of ARIMA $(0,1,1)$; fatal cases, is given as,

$Y_{t}-Y_{t-1}=e_{t}-\theta e_{t-1}$

$Y_{t}=Y_{t-1}+e_{t}-\theta e_{t-1}$

Substituting the value of $\theta$ as given in Figure (7), the model for the fatal cases becomes,

$Y_{t}=Y_{t-1}+e_{t}+0.406170 e_{t-1}$

And finally, the general difference of ARIMA $(1,1,1)$; Total cases, is given as,

$Y_{t}-Y_{t-1}=\psi\left(Y_{t-1}-Y_{t-2}\right)+e_{t}-\theta e_{t-1}$

$Y_{t}=(1+\psi) Y_{t-1}-\psi Y_{t-2}+e_{t}-\theta e_{t-1}$

Substituting the values of $\psi$ and $\theta$ as given in Figure (7), the model for the Minor cases becomes,

$Y_{t}=0.212321 Y_{t-1}+0.787679 Y_{t-2}+e_{t}-0.519769 e_{t-1}$

\section{Discussion}

One of the major concerns in Nigeria is the increasing Road traffic accident, which is at a disturbing rate. Federal Road Safety Corps (FRSC) of Nigeria recognizes the negative impacts of road safety accident and has commended the positive contribution of road safety researches as necessary tools to have significant accident initiatives. This research is carried out in order to identify the patterns of road traffic accident cases; the minor cases, the serious cases, the fatal cases and the total cases, by developing appropriate time series ARIMA models and predicts 7 years cases of road traffic accident (minor, serious, fatal and total cases) along the Nigeria's motorway.

Time series analysis of the data from the years 1960-2013 showed that patterns of road traffic accident cases are increasing (on average) along the Nigeria's motorway. The most widely used conventional method of time series known as Autoregressive Integrated Moving Average (ARIMA) model, also known as Box-Jenkins method was applied to the annual cases of road traffic accident data in Nigeria from 1960-2013 to determine patterns of road traffic accident cases along the Nigeria's motorways. After identifying various tentative models, the appropriate models for the accident cases (minor, serious, fatal and total cases) are as follows.

ARIMA $(1,1,1)$ was used to model the minor and total cases, ARIMA $(1,1,0)$ was used to model the serious cases, while ARIMA $(0,1,1)$ model was for the fatal cases using the data from 1960-2011. The adequacy and performance of the model were tested on the remaining data from 2012 to 2013.

We provide 7 years forecasts of the cases of road accident using the models developed and they showed that road traffic accident cases examined; minor cases, serious cases, fatal cases and total cases would continue to increase. This study provides reliable and genuine information that could be useful for determining road accident rate on Nigeria's motorways and provide necessary prevention for the unwanted act. This study would also be used for providing important information to increase the level of awareness among stakeholders concerning road safety, since the problem has become a growing issue in Nigeria. More so, in setting priorities when planning road traffic accident interventions. Most Importantly, this study would provide expected benefit to the road users, Road Safety Corps, researchers and other stakeholders in understanding the rate of the cases of road accident.

\section{Recommendation}

With the results at hand, it is very obvious that if government remain nonchalant and individuals are also waiting for government to do everything, the cases will continue to increase (on average) according to the forecast values. Note that the models should not be used for a long time forecast because it will results to unnecessarily large forecast. To avoid increase in road traffic accident, the following must be taking care of; Road Safety Agency should create awareness program for the citizens so as to inform (or remind) them of the rules and regulations. Phrases like "Do not make phone call while driving", "It's better to be late that to be late", "Do not drink and drive", and so on, should be found on car stickers, on billboard, in advertisement and other noticeable place for the drivers. This awareness can be done on television stations, radio stations, billboard, and so on.

Also, the law makers should give strict and immediate punishment for lawbrakers. Once some people are punish for violating the rules and regulations, it would serve as lessons for others. Moreover, the awareness should not be limited to drivers alone. The entire citizens must also be aware of the rules and regulations of Road Traffic. Like the use of over-head bridge instead of crossing high-way roads; how to rescue victims immediately incase of accidents, and so on.

Maintenance of motorways is also a key factor in reducing road traffic accident. Government should always ensure the maintenance of roads and provision of alternative routes (in case of very busy roads). More so, there should be 
special road for big vehicles like trucks, Lorries, and so on.

Furthermore, government and Road safety Agency should not be left alone to solve these problems. Since researchers know fact about figures, besides analyzing the cases of road traffic accidents, they should also be involved in educating the masses about the rate at which road traffic accident is increasing. This would also go a long way in reducing the accident cases.

\section{References}

Agyemang, B., Abledu, G. K., \& Semevoh, R. (2013). Regression Analysis of Road Traffic Accidents and Population Growth in Ghana. International Journal of Business and Social Research, 3(10), 41-47. Retrieved from http://thejournalofbusiness.org/index. php/site/article/view/290

Box, G. E. P., Jenkins, G. M., \& MacGregor, J. F. (1974). Some recent advances in forecasting and control. Applied Statistics, 158-179.

Hosseini, M. H., Yavarifar, B., \& Yavarifar, P. (2014). Studying of the Effect of Organizational Flexibility on Market and Sales Growth ( A Case Study of Workshops in the Automobile Services Industry ), 3(8), 31-33.

Mohan, P., Padmanabhan, V. N., \& Ramjee, R. (2008). Nericell: rich monitoring of road and traffic conditions using mobile smartphones. In Proceedings of the 6th ACM conference on Embedded network sensor systems (pp. 323-336). ACM.

Nihan, N. L., \& Holmesland, K. O. (1980). Use of the Box and Jenkins time series technique in traffic forecasting. Transportation, 9(2), $125-143$.

Okutu, J. K. (2011). Time series analysis of road traffic accidents in ghana, a case study of accra-tema motorway, greater accra region thesis submitted to the institute of distance learning. Institute of distance learning, kwame nkrumah university of science and technology.

Organization, W. H. (2013). Global status report on road safety. Injury Prevention, 318. doi:http://www.who.int/violence_injury_ prevention/road_safety_status/2013/en/index.html

Peden, M. (2004). World report on road traffic injury prevention. World Health Organization Geneva.

Promotion, S., \& Prevention, I. (2013). Prediction Of Fatal Road Traffic Crashes In Iran Using The Box-Jenkins Time Series Model Ayad Bahadori Monfared Hamid Soori Yadollah Mehrabi Hossein Hatami Ali Delpisheh, 3(4), 425-430.

Series, T., As, A., For, T., Of, E., Traffic, R., \& In, S. (2006). Prognosis of traffic safety •, 1-4.

Wu, C. H. (2013). ARIMA Models are Clicks Away. In Applied Mechanics and Materials (Vol. 411, pp. 1129-1133). Trans Tech Publ. 